\title{
A importância da higienização das mãos nas unidades de terapia intensiva: os perigos das infecções relacionadas à assistência à saúde
}

\author{
The importance of hand hygiene in intensive care units: the dangers of healthcare-related \\ infections
}

La importancia de la higiene de las manos en las unidades de cuidados intensivos: los peligros de las infecciones relacionadas com la salud

Davi de Aguiar Portela ${ }^{1}$, Alba Angélica Nunes Mouta ${ }^{2 *}$, Antônio Renan Rodrigues Alves ${ }^{1}$, Francisca Cadidja Ribeiro de Almeida ${ }^{1}$, Augusto César Beltrão da Silva ${ }^{1}$, Priscila Favoritto Lopes ${ }^{2}$, Brisa Fideles Gândara², Érica de Araújo Silva Mendes², Virginia Araújo Albuquerque ${ }^{1}$, Renata Paula Lima Beltrão ${ }^{1,2}$.

\section{RESUMO}

Objetivo: Analisar a literatura sobre a adesão de técnicas de Higienização das Mãos (HM) em Unidade de Terapia Intensiva (UTI) neonatal e adulta e suas possíveis relações com infecções relacionadas à assistência de saúde (IRAS). Revisão bibliográfica: Embora a lavagem de mãos seja uma maneira eficiente de prevenir infecções em ambiente hospitalar, há uma baixa adesão por parte dos profissionais da saúde à sua prática. Os enfermeiros são os que mais utilizam da HM, enquanto os médicos e técnicos de enfermagem são os que menos aderem a essas técnicas. Há também uma menor ocorrência de aceitação da lavagem das mãos com o passar dos turnos de trabalho durante o dia. Considerações finais: A falta de adesão de HM pode generalizar as infecções em uma UTI, sendo visto a necessidade da criação de ações educativas para incentivar a conscientização e a adesão à $\mathrm{HM}$, da maneira correta, pelos profissionais de saúde.

Palavras-chave: Unidade de terapia intensiva, Desinfecção das mãos, Infecção hospitalar.

\begin{abstract}
Objective: To analyze the literature on the adherence of hand hygiene techniques $(\mathrm{HH})$ in neonatal and adult Intensive Care Units (ICU) and their possible relationships with healthcare-related infections (HAI). Literature review: Although hand washing is an efficient way to prevent infections in a hospital environment, there is a low adherence by health professionals to its practice. Nurses are the ones who use HH the most, while doctors and nursing technicians are the ones who least adhere to these techniques. There is also a lower occurrence of acceptance of hand washing with the passing of work shifts during the day. Final considerations: The lack of $\mathrm{HH}$ adherence can generalize infections in an ICU, seeing the need to create educational actions to encourage awareness and adherence to $\mathrm{HH}$, in the correct way, by health professionals.
\end{abstract}

Keywords: Intensive care units, Desinfection of hands, Cross infection.

\footnotetext{
1 Instituto de Educação Superior do Vale do Parnaíba (IESVAP). Parnaíba - PI.

2 Universidade Federal do Delta do Parnaíba (UFDPar). Parnaíba - PI.

*Email: angelicanmouta@gmail.com
} 


\section{RESUMEN}

Objetivo: analizar la literatura sobre adherencia a las técnicas de higiene de manos $(\mathrm{HH})$ en unidades de cuidados intensivos ( $\mathrm{UCl}$ ) neonatales y de adultos y sus posibles relaciones con infecciones relacionadas con la atención médica (HAI). Revisión bibliográfica: aunque el lavado de manos es una forma eficiente de prevenir infecciones en un entorno hospitalario, los profesionales de la salud se adhieren poco a esta práctica. Las enfermeras son las que más usan $\mathrm{HH}$, mientras que los médicos y los técnicos de enfermería son los que menos se adhieren a estas técnicas. También hay una menor incidencia de aceptación del lavado de manos con el paso de los turnos de trabajo durante el día. Consideraciones finales: La falta de adherencia a $\mathrm{HH}$ puede generalizar las infecciones en una $\mathrm{UCI}$, al ver la necesidad de crear acciones educativas para fomentar la conciencia y la adherencia a $\mathrm{HH}$, de manera correcta, por parte de los profesionales de la salud.

Palabras-clabe: Unidades de cuidados intensivos, Desinfección de las manos, Infección hospitalaria.

\section{INTRODUÇÃO}

Apenas no século XIX, quando o médico Ignaz Semmelweis (1818-1865) introduziu a lavagem das mãos com solução clorada, após necropsias e antes de atendimentos a partos, com notória redução das taxas de mortalidade puerperal, foi observada a necessidade de higienizar corretamente as mãos. Desse modo, em pouco tempo a higienização correta das mãos tornou-se a principal medida de controle de disseminação de microrganismo no ambiente hospitalar (SOARES MA, et al., 2019).

A higienização das mãos (HM)tem por objetivo remover material orgânico ou inorgânico e microrganismos, podendo comprometer a segurança e a qualidade da assistência se não realizada. A adesão a este procedimento, de modo habitual, transformou-se em uma maneira eficaz de promover a segurança à saúde, principalmente, em setores nos quais existem alta complexidade, necessitando de cuidados extremos, devido a vulnerabilidade dos pacientes, que estão em grave estado geral. A HM é um procedimento simples e barato e é eficaz na promoção do controle de infecções e no aumento da qualidade no cuidado prestado ao paciente, auxiliando na redução de custos e de morbimortalidade, fenômenos esses que são requisitos fundamentais na busca por eficiência na área da saúde (VASCONCELOS RO, et al., 2018).

Nessa perspectiva, na Unidades de Terapia Intensiva (UTI) há uma grande quantidade de pacientes em grave estado geral, que necessita constantemente de procedimentos e de cuidados, favorecendo a disseminação de Infecção relacionadas à assistência à saúde (IRAS), caracterizadas por se relacionarem com procedimentos assistenciais (MELO LLS, et al., 2009). A UTI destaca-se como o setor com maior risco para aquisição de infecção hospitalar e disseminação da resistência bacteriana, considerando o tipo de paciente, a alta frequência de uso de antibióticos, o contato profissional/paciente e a ruptura da barreira tecidual dos pacientes submetidos a procedimentos invasivos. (OLIVEIRA AC, et al., 2009).

As infecções hospitalares são agravadas pela capacidade da pele de abrigar microrganismos e transferilos entre locais diferentes, ocorrendo diretamente ou não, e são agravadas pela falta de adesão à HM entre os profissionais de saúde (SOARES MA, et al., 2019). As infecções adquiridas durante as hospitalizações ou até 48 horas após alta são consideradas IRAS, bem como as adquiridas no período intraparto, durante a hospitalização ou até 48 horas após a alta, com exceção às infecções advindas da placenta (MARTINEZ MR, et al., 2009).

Cientes de que as mãos dos profissionais de saúde constituem o principal veículo de transmissão de microrganismos, o procedimento correto de HM seria uma obrigação profissional para redução deste perigo. Geralmente, nesses locais há placas indicativas sobre a maneira correta de higienização, sendo indicado lavar as mãos com água e sabão entre 40 e 60 segundos ou o uso de solução alcoólica por 20 a 30 segundos. Os insumos para os atos devem sempre ser disponíveis para os profissionais, pacientes e acompanhantes (BATHKE J, et al., 2013). 
Em 2005, a Organização Mundial da Saúde (OMS) divulgou o desafio global de segurança ao paciente, intitulado como "cuidado limpo é cuidado mais seguro", com o objetivo de mobilizar os países a agirem no controle e prevenção das IRAS, focando na prática da HM entre os profissionais da área.

Esse programa enfoca cinco momentos em que a HM devem ser realizadas, que seriam: antes de contato com paciente, antes da realização de procedimento asséptico, após exposição a fluidos corporais, após contato com paciente e após contato com ambiente próximo ao paciente. Entretanto, em uma pesquisa observacional feita em um hospital na região sul do Brasil, somente em $28,6 \%$ dos momentos observados a equipe médica higieniza as mãos como deveria (RAIMONDI DC, et al., 2017).

Apesar de todas as evidências apontarem para a importância da HM na prevenção de transmissão das infecções hospitalares e dos seus efeitos na redução das taxas de infecção, os profissionais de saúde não dão a devida importância a uma ação tão simples e acabam por contribuir com os mecanismos básicos da dinâmica de transmissão das doenças infecciosas. A negligência por parte dos profissionais da saúde em não adotar a prática de higienizar as mãos frequentemente é um problema mundial. Os dados da OMS sugerem que essa baixa adesão dos profissionais está relacionada à incorporação da prática diária e ao hábito, e não a falta de conhecimento teórico (PRIMO MGB, et al., 2010).

Diante da relevância desse assunto, esse trabalho objetiva analisar através de uma revisão narrativa sobre a prática de HM nas UTI e avaliar os impactos da higienização correta na redução das taxas de IRAS.

\section{REVISÃO BIBLIOGRÁFICA}

\section{O perigo das infecções cruzadas no ambiente hospitalar}

As IRAS afetam milhares de doentes em todo o mundo, levando-os a doenças mais graves e prolongando sua permanência nos hospitais. Isso ocorre por diversas razões e existem muitos mecanismos que favorecem seu aparecimento, sendo a principal, a transmissão de microrganismos pelos profissionais da área da saúde aos pacientes.

Considerando-se que o hospital seja um local de cura e de atendimento àqueles que possuem alguma necessidade de saúde, torna-se imprescindível uma assistência humanizada e segura perante suas ações assistenciais. Porém, esta não é a realidade enfrentada, visto que, ainda observa-se altos índices de infecções hospitalares, comprometendo a assistência prestada nesses locais, que poderiam ser prevenidas com medidas de controle como a HM (BELELA-ANACLETO ASC, et al., 2017).

Ao analisar um estudo do tipo coorte ocorrido em uma UTI de um hospital universitário de Belo Horizonte, em Minas Gerais, foi visto que muitos pacientes apresentaram mais de uma infecção, em sítios diferentes do corpo. Essa realidade é evidente porque a permanência hospitalar expõe os pacientes a outros fatores de riscos, seja em consequência de sua gravidade ou da maior exposição ao risco de infecções cruzadas, fazendo eles serem exibidos à maior pressão seletiva no ambiente hospitalar. Esse fato se agrava em virtude de $42,5 \%$ dos pacientes com IRAS evoluírem a óbito, o que revela a importância do estabelecimento de intervenções para a prevenção das IRAS (OLIVEIRA AC, et al., 2012).

No que diz respeito à segurança do paciente prestada no ambiente hospitalar, é visto que a responsabilidade profissional não se adere às práticas de $\mathrm{HM}$ e de aspectos éticos relacionados a essa conduta. Por isso, a higienização das mãos não deve ser vista apenas como uma prática opcional, mas deve ser encarada como obrigação, fundamental para a garantia de uma assistência segura. Por ser uma das mais importantes medidas de prevenção e controle das IRAS, a HM é considerada um dos pilares para a segurança do paciente e para o combate às infecções.

Relatos de surtos em UTIs por microrganismos multirresistentes Gram-negativos têm sido progressivos nas últimas décadas, constituindo-se uma ameaça à segurança do paciente e à saúde pública em todo o mundo, estando relacionados à baixa adesão da HM (SOUZA LM, et al., 2015). 


\section{A importância da lavagem de mãos na UTI}

Embora seja um procedimento de intervenção simples, a lavagem de mãos é pouco observada entre os profissionais de saúde. Também é observado que muitos profissionais realizam a HM, mas de forma errônea, o que influencia no aumento ou redução de contágios em hospitais. A implantação de programas de precaução de infecções hospitalares constitui uma das melhores alternativas para a prevenção de IRAS, havendo estudos comprovantes de uma adesão de até $6 \%$ das técnicas corretas entre profissionais (MARTINEZ MR, et al., 2009). Além disso, a HM é muito mais utilizada pelos profissionais para proteção pessoal, deixando a preocupação com o paciente em segundo lugar. Esse fato é acrescentado da grande quantidade de profissionais que acreditam na suficiência da frequência com que realizam a lavagem de mãos (BATHKE J, et al., 2013).

A prática de HM tem uma baixa adesão que pode estar relacionada a inúmeros problemas multifatoriais, como exemplo pode-se citar problemas relacionados aos profissionais de saúde, como estresse excessivo, alta carga de trabalho e maus hábitos, ou problemas relacionados ao ambiente, como o desfavorecimento em virtude da localização das pias serem distantes dos locais onde há uma maior necessidade para lavar as mãos. Entretanto, outro problema bem abrangente do sistema público de saúde é a má coordenação dos recursos destinados a compra de dispositivos que ajudam na restrição da disseminação de infecções, como sabão antisséptico e álcool em gel, os quais são necessários para todos os ambientes altamente infecciosos (FARIAS MEL, et al., 2019).

Pesquisadores citam as principais justificativas para a baixa adesão à HM, denominadas de barreiras para HM: esquecimento, desconhecimento, distância da pia, falta de tempo, irritação da pele e falta de materiais. Dessa forma, necessita-se de estratégias multimodais para eliminar essas barreiras, aumentando a adesão à $\mathrm{HM}$ no cenário do estudo. Os resultados dessas estratégias refletiriam na mudança de cultura e de comportamento dos profissionais de saúde, com impacto nos indicadores de adesão à HM (SOUZA LM, et al., 2015).

Nesse sentido, a maioria dos profissionais da saúde referiram não haver fatores de estímulo ou impedimentos para higienizar-se. Entretanto, aos que disseram haver, os principais fatores foram: prejuízos a pele, ausência de insumos, esquecimento e desconhecimento, ceticismo e falta de exemplo de outros colegas. Houve também a falta do uso de soluções alcoólicas, cujo incentivo nas UTIs deve ser alto, já que tem um grande respaldo pela diretriz nacional de HM (BATHKE J et al., 2013). Segundo uma análise, a maior frequência de aceitação das práticas de HM acontece após o contato com o paciente $(42,1 \%)$, que é maior entre os enfermeiros. Em contrapartida, as menores adesões vieram antes da realização de procedimentos antissépticos $(6,3 \%)$ e antes de contato com o paciente (12\%), momentos decisivos para a disseminação das IRAS (ALVIM ALS, et al., 2018).

Em um estudo conduzido entre maio e outubro de 2007, em um hospital filantrópico de grande porte, no qual atende a rede pública e a rede privada, foi demonstrado baixa adesão às medidas de precaução pelos profissionais de saúde, que pode estar associado a vários aspectos do comportamento humano, incluindo a falsa percepção de um risco invisível e a subestimação da responsabilidade individual na elevação das taxas de infecção hospitalar, pois menos da metade desses profissionais não tinham o conhecimento adequado para a higienização correta das mãos (OLIVEIRA AC, et al., 2009).

Tal problemática se amplia nas UTIs, haja vista que entre os principais erros ocorridos por um grupo de profissionais na assistência de saúde, a higienização inadequada das mãos está em terceiro lugar, com uma ocorrência de $67 \%$, perdendo somente por não elevação das grades do leito, perda de cateteres, sondas e drenos (83\%) e por extubações acidentais (72\%). Esses erros são frequentemente relacionados a vergonha, culpa e medo de punições, o que colabora para a omissão deles e, consequentemente, a sua não intervenção (DUARTE SCM et al., 2016). A equipe de enfermagem é a que mais permanece em contato direto com os pacientes e totalizou $60 \%$ de efetividade na adesão da HM quando tinham oportunidade, tendo uma frequência de erros menor do que a observada pelos outros profissionais (SILVA BR, et al., 2018). 


\section{A necessidade da HM para a segurança do paciente}

Em um estudo ocorrido com o banco de dados de um hospital, referente no atendimento a pacientes com traumas, localizado em Porto Alegre, constatou-se a menor adesão da HM dos técnicos de enfermagem $(29,8 \%)$, fato esse que é muito preocupante, pois eles são os profissionais que estão direta e ininterruptamente com mais contato junto aos pacientes. Assim, pelo maior contato físico, acrescido da não realização dessa prática, coloca o paciente em maior risco para infecções. Esse fato se diferencia da maioria, pois em outros estudos é visto que os enfermeiros têm maior adesão da $\mathrm{HM}$, em comparação a outros profissionais da saúde (SOUZA LM, et al., 2015). A adoção da prática de HM, é de grande importância devido ao fato de que grande percentual de IRAS podem ser evitadas, uma vez que a maioria dos microrganismos associados à microbiota transitória das mãos, ou seja, aquela adquirida pelo contato com pessoas ou materiais colonizados ou infectados, poderiam ser facilmente eliminados por meio de uma adequada lavagem (COELHO MS, et al., 2011).

Em um estudo realizado em uma UTI infantil de um hospital público de Belo Horizonte, é ressaltado que $36,3 \%$ dos profissionais tinham o conhecimento adequado das medidas de controle para a disseminação de doenças infecciosas. As diferentes abordagens na formação de cada profissional influenciam na divergência de conhecimentos em relação a adesão de HM e o comportamento deles em relação as precauções quando há contato. Analisando as categorias profissionais o estudo constatou que o enfermeiro é o profissional com maior adesão à $\mathrm{HM}(45 \%)$. Já os auxiliares de enfermagem e os técnicos de radiologia a menor adesão a esta prática ( $16 \%$ e $9 \%$ respectivamente). Frente a essas constatações verifica-se que a adesão a prática de higienização ainda é insuficiente, principalmente entre os profissionais de nível médio (OLIVEIRA AC, et al., 2016).

Foi constatado em outro estudo, feito pelo banco de dados eletrônicos do Serviço de Controle de Infecção Hospitalar, em um hospital localizado na região sul do Brasil, que os enfermeiros e os técnicos de enfermagem apresentam a maior adesão à higiene das mãos após o risco de exposição (85\% e 64,7\% respectivamente). Ele também ressaltou que os profissionais de saúde apresentaram uma adesão de 55,6\% a higiene das mãos após risco de exposição a fluídos e 58,9\% só aderiram a prática após contato com o paciente, sendo os dois principais momentos que apresentaram uma maior adesão a prática de HM (SOUZA LM, et al., 2015). Os profissionais de saúde devem agir de forma a propiciar uma atuação como educadores, tornando-se referências para todos aqueles que fazem parte da equipe e agindo de maneira correta sempre higienizandose com água e sabão ou usando álcool 70\%. Essas atitudes são benéficas a outros profissionais, pois um dos motivos citados pela baixa adesão da HM foi que há poucos exemplos de colegas de trabalho que realmente higienizam-se, fazendo ocorrer um efeito dominó entre todos do ambiente hospitalar (PRIMO MGB, et al., 2010).

Não somente foi visto uma baixa adesão a HM pelos profissionais, como também foi analisado a gradativa diminuição da lavagem de mãos no decorrer do dia. Em verdade, foi observado um maior quantitativo de adesões durante a manhã, que chegou a ser maior que 50\%. No turno da tarde, teve uma média de $41,8 \%$ pelos técnicos de enfermagem e $42,3 \%$ pelos enfermeiros. Neste presente estudo não foi observado a adesão de HM durante o turno da noite. Salienta-se citar que somente $33,3 \%$ dos enfermeiros e $51,8 \%$ dos técnicos de enfermagem receberam medidas interventivas de HM, como treinamentos e capacitações. A falta de medidas interventivas é um fator negativo, considerando a necessidade de programas que almejam a estratégias para a melhoria de ações sociais que garantam a proteção de pacientes e profissionais da saúde (VASCONCELOS RO, et al., 2018).

Os profissionais de saúde estão expostos ao risco de adquirir infecções pelo contato direto com o paciente e seu ambiente. Entretanto, quando o contato envolve fluídos corporais e regiões potencialmente contaminadas, a adesão a HM aumenta devido à busca do autocuidado por parte dos profissionais. Por outro lado, a não realização nos procedimentos antes do contato com o paciente ou de procedimento asséptico se torna um risco à segurança dos pacientes, haja vista que acarreta em transmissões de microrganismos do ambiente de assistência ao paciente. Além disso, os pacientes de UTI, por sua condição de saúde e tratamento, são mais vulneráveis às infecções e ao seu agravamento, fato esse demonstrante da necessidade da HM (SOUZA LM, et al., 2015). 
Um achado importante muito bem analisado foi que o conhecimento pode estar desvinculado do comportamento adequado. Nessa constatação, é visto a desassociação entre teoria e prática, fazendo supor que os profissionais são, algumas vezes, treinados para repetir mecanicamente e executar de forma acrítica os procedimentos. Há também a necessidade de se implementar atividades de orientação voltadas à equipe multidisciplinar, com apresentação periódica das taxas de infecção e de microrganismos resistentes (OLIVEIRA AC, et al., 2009).

Durante as análises dos profissionais, foi citado a efeito Hawthorne, que corresponde na melhoria do desempenho devido à observação de suas ações, o que pode motivá-los a produzir melhores resultados. Sendo assim, no cotidiano das UTls, a adesão de práticas de HM são bem menores do que previstos na coleta dos dados em questão. A categoria médica realizou a higiene de mãos, 22,2\% antes do contato com o paciente e $66,7 \%$ após o contato com o paciente, resultado este que diverge dos outros estudos analisados, os quais colocam os médicos e técnicos de enfermagem como os que menos aderem a HM. Em verdade, é importante citar também que a maioria dos profissionais analisados lavaram as mãos de maneira preconizada, porém não fazendo do método correto (SILVA BR, et al., 2018).

\section{A adesão nos cinco momentos para HM}

A HM após o contato com o paciente apresentou maior adesão entre os profissionais de saúde, corroborando com estudo que encontrou $12 \%$ antes do contato com o paciente e $45 \%$ após este contato. Embora não exista uma meta de adesão instituída mundialmente, a literatura afirma que os valores se encontram abaixo do desejado para segurança do paciente, atribuindo à interpretação errônea por parte dos profissionais de saúde de que o uso de luvas substitui a prática de $\mathrm{HM}$ e demonstram ainda que existe uma tendência dos profissionais ao autocuidado, visto que a maior adesão a prática é realizada após o contato com os pacientes (BATHKE J, et al., 2013).

Verificou-se maior adesão dos profissionais ao uso de luvas, contrastando com a baixa adesão à higienização das mãos, o que pode observar maior preocupação com a proteção individual, ignorando, por vezes, que as luvas não constituem uma proteção plenamente efetiva pela possibilidade de micro furos, de transmissão de microrganismos e que seu uso não substitui a $\mathrm{HM}$. A constatação do baixo número de profissionais com conhecimento adequado a respeito das precauções de contato é preocupante, uma vez que a resistência bacteriana tem aumentado e é incidente nas UTIs. Por outro lado, pesquisa realizada entre enfermeiros de um hospital público de Goiânia revelou que a maioria dos sujeitos apontou adequação cognitiva favorável à implementação das precauções padrão no cotidiano em relação à sua compreensão (OLIVEIRA AC, et al., 2009).

A constatação do baixo número de profissionais com conhecimento adequado a respeito das precauções de contato é preocupante, uma vez que a resistência bacteriana tem aumentado e é incidente nas UTIs. Por outro lado, uma pesquisa realizada entre enfermeiros de um hospital público de Goiânia revelou que a maioria dos sujeitos apontou adequação cognitiva favorável à implementação das precauções padrão no cotidiano em relação à sua compreensão (OLIVEIRA AC, et al., 2009). Muitos estudos científicos relatam uma correlação entre a HM e a redução na transmissão de infecções, visto que a HM na prevenção de transmissão das infecções hospitalares é baseada na capacidade da pele em abrigar microrganismos e transferi-los de uma superfície para a outra, por contato direto, pele com pele, ou indireto, por meio de objetos. Esses estudos têm mostrado a importância da implementação de práticas de HM na redução das taxas de infecções, pois essa prática, além de ser uma medida básica e barata, também é a maneira reconhecidamente mais eficiente para a prevenção de IRAS (SANTOS AAM, et al., 2002).

Com a realização, por um período de tempo de dois meses, de um programa de educação, relacionado a ensinar a prática correta de HM, para os profissionais de saúde de uma UTI clinico-cirúrgica de um hospital universitário do Rio de Janeiro, houve um aumento significativo na adesão de higienização entre todos os profissionais da equipe médica. Entretanto, nesse estudo não foi analisado a ocorrência de IRAS, mas sim de uma infecção específica (pneumonia associada a ventilação mecânica), e isso pode influenciar em não haver detalhes melhores sobre como a HM tem uma grande influência sobre as infecções em um ambiente hospitalar (ROMERO DNP. et al.,2018). 


\section{CONSIDERAÇÕES FINAIS}

Em síntese, foi observado que a HM dos profissionais de saúde encontra-se muito deficitária. Os resultados apresentados são muito preocupantes e requer bastante atenção, uma vez que estes profissionais encontram-se em contato direto com os pacientes. Ressalta-se ainda que é reduzida a adesão à HM pela equipe de saúde em momentos antes do contato com o paciente, apresentando maior adesão nos momentos após o contato, ou seja, houve maior adesão do profissional de saúde à HM nas indicações que refletem proteção do profissional, quando comparadas àquelas relativas ao paciente. Diante do exposto, observou-se a necessidade de realização de ações educativas para incentivar a conscientização pelos profissionais de saúde, visto que a HM é a prática mais simples e eficiente no controle de IRAS.

\section{REFERÊNCIAS}

1. ALVIM ALS, et al. Avaliação das práticas de higienização das mãos em três unidades de terapia intensiva. Revista de Epidemiologia e Controle de Infecção, 2018;9(1):55-59.

2. BATHKE J, et al. Infraestrutura e adesão à higienização das mãos: desafios à segurança do paciente. Revista Gaúcha de Enfermagem, 2013;34(2):78-85

3. BELELA-ANACLETO ASC, et al. Higienização das mãos como prática do cuidar: reflexão acerca da responsabilidade profissional. Revista Brasileira de Enfermagem, 2017;70(2):442-5.

4. BRASIL, Ministério da Saúde. Agência Nacional de Vigilância Sanitária (ANVISA). Segurança do Paciente. Higienização das Mãos. Brasília-DF, 2009.

5. COELHO MS, et al. Higienização das mãos como estratégia fundamental no controle de infecção hospitalar: um estudo quantitativo. Revista Enfermería Global, 2011;21:1-12.

6. DUARTE SCM, et al. Caracterização de erros na assistência de enfermagem em terapia intensiva. Revista Cogitare Enfermagem, 2016;21:01-08.

7. FARIAS MEL, et al. Adesão à higiene das mãos antes e após intervenções educativas do dia mundial para higienização das mãos em um hospital universitário. Revista Eletrônica Acervo e Saúde, 2019;11(16):e1354.

8. MARTINEZ MS, et al. Adesão à técnica de lavagem de mãos em Unidade de Terapia Intensiva Neonatal. Revista Paulista de Pediatria, 2009;27(2):179-85.

9. MELO LLS, et al. Flora fúngica no ambiente da Unidade de Terapia Intensiva Pediátrica e Neonatal em hospital terciário. Revista Paulista de Pediatria, 2009;27(3):303-8.

10. LUANGASANATIP N, et al. Comparative efficacy of interventions to promote hand hygiene in hospital: systematic review and network meta-analysis. BMJ, 2015;101h;3 28.

11. OLIVEIRA AC, et al. Infecções relacionadas à assistência em saúde e gravidade clínica em uma unidade de terapia intensiva. Revista gaúcha de Enfermagem, 2012;33(3):89-96.

12. OLIVEIRA AC, et al. Conhecimento e comportamento dos profissionais de um centro de terapia intensiva em relação à adoção das precauções de contato. Revista Latino-Americana de Enfermagem, 2009;17(5):625-31.

13. PRIMO MGB, et al. Adesão à prática de higienização das mãos por profissionais de saúde de um Hospital Universitário. Rev. Eletr. Enf., 2010;12(2):266-71.

14. RAIMONDI DC, et al. Higienização das mãos: adesão da equipe de enfermagem de unidades de terapia intensiva pediátricas. Revista Cuidarte, 2017;8(3):1839-48.

15. ROMERO DMP, et al. Efeitos da implementação de um programa de educação de higienização das mãos entre profissionais de uma UTI: análise de séries temporais interrompidas. Revista J. Bras Pneumol, 2019;45(5):e20180152.

16. SANTOS AAM, et al. Higienização das mãos no controle das infecções em serviços de saúde. Revista de Administração em Saúde, 2002; 4(15):1-14.

17. SILVA BR, et al. Monitoramento da adesão à higiene das mãos em uma unidade de terapia intensiva. Revista Enfermagem Uerj, 2018; 26:33087.

18. SOARES MA, et al. Microrganismos multirresistentes nas mãos de profissionais da saúde em Unidades de Terapia Intensiva. Revista de Epidemiologia e Controle de Infecção, 2019;9(3):187-192.

19. SOUZA LM, et al. Adesão dos profissionais de terapia intensiva aos cinco momentos da higienização das mãos. Revista Gaúcha de Enfermagem, 2015;36(4):21-8.

20. VASCONCELOS RO, et al. Adesão à higienização das mãos pela equipe de enfermagem em unidade de terapia intensiva. Revista Enfermería Global, 2018;50:446-461. 